\title{
Association of Reproductive History With Brain MRI Biomarkers of Dementia Risk in Midlife
}

Eva Schelbaum, BA, Lacey Loughlin, BA, Steven Jett, MA, Cenai Zhang, MS, Grace Jang, BA, Niharika Malviya, BA, Hollie Hristov, NP, Silky Pahlajani, MD, Richard Isaacson, MD, Jonathan P. Dyke, PhD, Hooman Kamel, MD, Roberta Diaz Brinton, PhD, and Lisa Mosconi, PhD

Neurology ${ }^{\circledR}$ 2021;97:e2328-e2339. doi:10.1212/WNL.0000000000012941

\author{
Correspondence \\ Dr. Mosconi \\ lim2035@med.cornell.edu
}

\begin{abstract}
\section{Background and Objectives}

To examine associations between indicators of estrogen exposure from women's reproductive history and brain MRI biomarkers of Alzheimer disease (AD) in midlife.

\section{Methods}

We evaluated 99 cognitively normal women $52 \pm 6$ years of age and 29 men $52 \pm 7$ years of age with reproductive history data, neuropsychological testing, and volumetric MRI scans. We used multiple regressions to examine associations among reproductive history indicators, voxel-wise gray matter volume (GMV), and memory and global cognition scores, adjusting for demographics and midlife health indicators. Exposure variables were menopause status, age at menarche, age at menopause, reproductive span, hysterectomy status, number of children and pregnancies, and use of menopause hormonal therapy ( $\mathrm{HT})$ and hormonal contraceptives $(\mathrm{HC})$.
\end{abstract}

\section{Results}

All menopausal groups exhibited lower GMV in $\mathrm{AD}$-vulnerable regions compared to men, with perimenopausal and postmenopausal groups also exhibiting lower GMV in temporal cortex compared to the premenopausal group. Reproductive span, number of children and pregnancies, and use of $\mathrm{HT}$ and $\mathrm{HC}$ were positively associated with GMV, chiefly in temporal cortex, frontal cortex, and precuneus, independent of age, APOE $\varepsilon 4$ status, and midlife health indicators. Although reproductive history indicators were not directly associated with cognitive measures, GMV in temporal regions was positively associated with memory and global cognition scores.

\section{Discussion}

Reproductive history events signaling more estrogen exposure such as premenopausal status, longer reproductive span, higher number of children, and use of HT and HC were associated with larger GMV in women in midlife. Further studies are needed to elucidate sex-specific biological pathways through which reproductive history influences cognitive aging and $\mathrm{AD}$ risk. 


\section{Glossary}

$\mathbf{A} \beta=\beta$-amyloid $\mathbf{A D}=$ Alzheimer disease $; \mathbf{C I}=$ confidence interval; $\mathbf{G M}=$ gray matter $\mathbf{G M V}=$ gray matter volume; $\mathbf{H C}=$ hormonal contraceptive; HT = hormone therapy; $\mathbf{M T L}=$ medial temporal lobe; $\mathbf{T I V}=$ total intracranial volume; $\mathrm{TT}=$ testosterone therapy; VOI = volume of interest; $\mathbf{W C M}=$ Weill Cornell Medicine.

Recent studies identify female-specific reproductive history events as possible biological underpinnings of the higher prevalence of Alzheimer disease $(\mathrm{AD})$ in women. ${ }^{1,2} \mathrm{AD}$ pathology begins in the 10- to 20-year presymptomatic phase, ${ }^{3}$ proximate with the midlife menopause transition in women. ${ }^{4-7}$ Preclinical evidence for neuroprotective effects of estrogens ${ }^{8,9}$ also suggests a link between female fertility and $\mathrm{AD}$.

However, the effects of estrogen exposure on $\mathrm{AD}$ risk remain unclear. In some studies, a longer reproductive span was associated with lower risk of dementia or cognitive decline in older postmenopausal women..$^{10-13}$ An earlier age at menarche ${ }^{10}$ or a later age at menopause ${ }^{10,12-14}$ was also associated with reduced risk of dementia or cognitive decline. The opposite effect has also been noted, with a longer reproductive span and an earlier age at menopause being associated with a higher dementia risk. ${ }^{15}$ In another study, these negative associations were significant only among women carrying the APOE $\varepsilon 4$ genotype, ${ }^{16}$ the major genetic risk factor for late-onset $\mathrm{AD} .{ }^{17}$ In addition, other studies reported no associations between reproductive span, ${ }^{12,18,19}$ age at menopause, ${ }^{11,18,19}$ or age at menarche $e^{11,15,16,18,19}$ and dementia risk. Number of children and number of pregnancies were also associated with a higher ${ }^{14,18-20}$ or lower risk of dementia. ${ }^{11}$ Furthermore, while observational studies generally indicate decreased dementia incidence with menopause hormone therapy (HT) use, clinical trials show increased dementia risk among older postmenopausal women or no effects. ${ }^{21,22}$

No brain imaging studies have evaluated the impact of reproductive health indicators on $\mathrm{AD}$ risk in midlife, when potential for preservation of cognitive function is greatest.

Herein we evaluate associations between reproductive history indicators and MRI-based gray matter (GM) volume (GMV), a well-established biomarker of neuronal aging and $\mathrm{AD}$ related neurodegeneration, ${ }^{23}$ in women in midlife at risk for $\mathrm{AD}$ and compared to age-controlled men.

\section{Methods}

\section{Study Population}

This observational cohort study focuses on cognitively normal women and men 40 to 65 years of age with risk factors for lateonset $\mathrm{AD}$ such as a family history and/or APOE $\varepsilon 4$ genotype. Participants were recruited at Weill Cornell Medicine (WCM) between 2018 and 2021 by self-referral, flyers, and word of mouth, as described previously. ${ }^{4-7}$ All participants received clinical, cognitive, laboratory, and brain MRI examinations within $\approx 3$ months.
Exclusion criteria included medical conditions that may affect brain structure or function (e.g., stroke, head trauma, any neurodegenerative diseases, major psychiatric disorders, hydrocephalus, intracranial mass, and infarcts on MRI), use of psychoactive medications, and contraindications to MRI. Participants had Mini-Mental State Examination score of $\geq 26$ and normal cognitive test performance by age and education. ${ }^{4-7}$

APOE genotype was determined with standard quantitative PCR procedures. ${ }^{4-7}$ Participants carrying 1 or 2 copies of the APOE $\varepsilon 4$ allele were grouped together as APOE $\varepsilon 4$ carriers and compared to noncarriers.

\section{Standard Protocol Approvals, Registrations, and Patient Consents}

All participants provided written consent to participate in this WCM Institutional Review Board-approved study.

\section{Data Availability}

Deidentified data may be made available to qualified investigators from the WCM Institutional Review Board/ Institutional Data Access on reasonable request.

\section{Reproductive History Measures}

We used questionnaires and semistructured interviews to collect information related to reproductive history from all participants, as detailed in eTable 1, links.lww.com/WNL/B612.

The following exposures were examined for all female participants:

- Menopausal status was examined as a categorical variable comparing premenopausal, perimenopausal, and postmenopausal groups, defined on the basis of the Stages of Reproductive Aging Workshop criteria ${ }^{24}$ and laboratory hormone assessments.

- Menopause type was examined as a categorical variable comparing spontaneous and induced menopause groups (hysterectomy and/or oophorectomy before menopause).

- Age at menarche was examined as a continuous measure and after grouping responses into 2 categories: $<13$ and $\geq 13$ years. ${ }^{10}$

- Number of children and number of pregnancies were examined as continuous measures and after grouping responses into 3 categories: 0 children, 1 child, and $\geq 2$ children. We also collected information on age at firstborn (years).

- HT use was examined as a categorical variable comparing HT never users to past and current users. We also collected information on duration of use (years). 
- Hormonal contraceptive (HC) use was examined as a categorical variable comparing never users to past and current users. We also collected information on duration of use (years).

The following exposures were examined for postmenopausal women only:

- Age at menopause was examined as a continuous measure and after grouping responses into 2 categories: $<51$ and $\geq 51$ years. $^{10}$

- Reproductive span, the difference between age at menopause and age at menarche, was examined as a continuous measure and after grouping responses into 2 categories: $<39$ and $\geq 39$ years. ${ }^{10}$

The following exposures were examined for male participants:

- Andropause status was examined as a categorical variable comparing preandropause vs postandropause according to the Aging Males' Symptoms scale ${ }^{25}$ and laboratory hormone assessments.

- Testosterone therapy (TT) use was examined as a categorical variable comparing TT never users to past and current users. We also collected information on duration of use (years).

- Number of children and age at firstborn were assessed with the same procedures as above.

\section{Cognitive Scores}

We focused on tests with known sensitivity to estrogen levels, ${ }^{7,26}$ including verbal memory (Rey Auditory Verbal Learning Test and Wechsler Memory Scale logical memory delayed recall tests), executive function (Trail Making Test B and F-A-S), and language (object naming) tests. Our main outcome was a composite memory score obtained by first $z$ scoring each memory measure and then averaging the 2 measures. We also obtained a global cognition score by first computing an executive function score (average of $z$-scored executive function tests) and a language score ( $z$-scored language test) and then averaging across these domains and the memory domain.

\section{Brain Imaging Acquisition and Analysis}

All participants received 3-dimensional T1-weighted MRI scans (brain volume imaging; $1.0 \times 1.0 \times 1.0-\mathrm{mm}$ resolution, 8.2-millisecond repetition time, 3.2-millisecond echo time, 25.6-cm field of view, $256 \times 256$ matrix) on a 3.0T GE Discovery MR750 scanner (GE Healthcare, Chicago, IL). Image analysis was performed with a fully automated image processing pipeline. ${ }^{4-6}$ Briefly, for each participant, MRI scans were coregistered to each other using the normalized mutual information routine of Statistical Parametric Mapping $\left(\right.$ SPM12) ${ }^{27}$ implemented in MatLab 7.8 and processed with voxel-based morphometry, including segmentation into GM, white matter, and CSF segments, Jacobian modulation to restore GMV using the unified segmentation algorithm, high- dimensional warping (DARTEL) of the segments, and application of an 8-mm full width at half-maximum smoothing kernel. ${ }^{27}$ We also obtained total intracranial volume (TIV) as the sum of GM, white matter, and CSF partitions.

\section{Covariates}

GMV analyses were adjusted by age and TIV, and cognitive analyses were adjusted by age. For exposures showing significant associations with outcome measures, we examined additional confounders, including APOE $\varepsilon 4$ status (carrier vs noncarrier) and midlife health indicators: self-reported smoking status (current, past, or never smoker), waist-tohip ratios, and hypertension diagnosis (as determined by our physicians using systolic blood pressure $\geq 140 \mathrm{~mm} \mathrm{Hg}$, diastolic blood pressure $\geq 90 \mathrm{~mm} \mathrm{Hg}$, or use of antihypertensive medications). Last, we examined exposure-specific confounders, including (1) hysterectomy status and HT use in analysis of menopausal status and reproductive span; (2) age at firstborn in analysis of number of children; (3) hysterectomy status and duration of use in analysis of HT effects; and (4) duration of use in analysis of HC effects. Analyses of menopausal status, age at menopause, and duration of reproductive span were repeated after the exclusion of participants with hysterectomy.

\section{Statistical Analysis}

Analyses were performed in Stata/MP version 15.1 (StataCorp, College Station, TX), SPSS version 25 (SPSS Inc, Chicago, IL), and SPM12. We used multiple linear regressions to examine associations between exposures (menopausal status, age at menarche, age at menopause, reproductive span, hysterectomy status, number of children, $\mathrm{HT}$ and $\mathrm{HC}$ use) and outcomes (GMV, memory and global cognition scores), including the covariates listed above. For the male cohort, analysis focused on associations between number of children and outcomes. We also tested for differences between each menopausal group and the male group.

For cognitive scores, results were examined using general linear models at $p<0.05$, corrected for multiple comparisons. For SPM12 analysis, we used a series of voxel-based general linear models with post hoc $t$ contrasts to test for associations between each exposure variable and GMV and to compare each menopause group to the male group. Statistical maps of main effects and post hoc comparisons were conservatively obtained by first applying an a priori masking image including a set of $\mathrm{AD}$-vulnerable regions and then a cluster-level smallvolume correction for multiple comparisons at $p<0.05$. The masking image was generated with the Automated Anatomical Labeling atlas and comprised inferior, middle, and superior temporal gyrus; medial temporal lobe (MTL; including hippocampus, amygdala, entorhinal cortex, and parahippocampal gyrus); posterior cingulate cortex; precuneus; fusiform gyrus; inferior, middle, and superior frontal cortex; inferior and superior parietal lobule; and basal ganglia. ${ }^{4,23}$ In addition, results were examined after application of an a priori GM mask to restrict analysis to GM-only voxels. Anatomic location of 
significant clusters was described with Montreal Neurological Institute coordinates. GMV expressed in units of GM density was extracted using volumes of interest (VOIs) at the peak of cluster significance for further analysis using Marsbar 0.44.

\section{Sensitivity Analysis}

There is evidence that voxel-based analysis is effective for larger cortical regions but may underestimate effects in $\mathrm{MTL}^{28}$ a region with higher anatomical specificity for cognitive aging and $\mathrm{AD} .^{23}$ Therefore, we performed a sensitivity analysis to test for associations between reproductive history exposures and MTL GMV as an a priori selected region using the VOI approach. We extracted and averaged GMV from MTL clusters identified in analysis of menopause status vs men, and we examined this measure as an additional MRI outcome using multiple regressions, adjusting by the same covariates as above.

We also examined associations between regional GMV extracted from the peak association clusters for each exposure, as well as from MTL, and cognitive measures. All results were considered significant at $p<0.05$.

\section{Results}

\section{Participants}

A total of 137 participants, including 106 women and 31 men, were enrolled. Of these, 9 were excluded because of incidental findings on MRI ( $n=5)$, artifacts on MRI $(n=1)$, or missing reproductive history reports $(\mathrm{n}=3)$. The remaining 128 participants, including 99 women and 29 men, were examined in this study. As shown in Table 1, there were no differences between men and women in clinical or cognitive data (memory $p=0.456$, global cognition $p=0.764$ ).

All women provided information about menopausal status, hysterectomy status, and HT use. The cohort included 15 premenopausal, 35 perimenopausal, and 49 postmenopausal women. Thirteen participants reported having had a hysterectomy/oophorectomy. Participants were 27\% current HT users, $4 \%$ past users, and $69 \%$ never users. All HT users except 7 provided information on duration of use, which averaged $5 \pm 4$ years.

One participant did not provide information on HC use. The remaining 98 participants included $9 \%$ current $\mathrm{HC}$ users, 53\% past users, and $38 \%$ never users. All HC users except 8 provided information on duration of use, which averaged $13 \pm 8$ years.

Eleven participants did not provide information on age at menarche. The remaining 88 participants were included in analyses of age at menarche. Of the 49 postmenopausal participants, 1 did not provide information on age at menarche, and 1 did not provide information about age at menopause. The remaining 47 postmenopausal participants with complete information were included in analyses of reproductive span.
Three participants did not provide information on number of children. Of the remaining 96 participants, $21 \%$ had no children, $17 \%$ had 1 child, and $62 \%$ had $\geq 2$ children.

As shown in Table 1, among men, 1 participant had laboratory findings consistent with andropause and reported taking TT, and another who was not in andropause reported taking TT in the past. Thus, we were unable to test for effects of andropause or TT on outcomes. Among men, 21\% had no children, $7 \%$ had 1 child, and $72 \%$ had $\geq 2$ children, comparable to the female group.

\section{Reproductive History Indicators and Brain Biomarkers}

\section{Menopause Status}

Negative associations between menopause status and GMV were observed in inferior temporal gyrus $(p=0.049)$ and borderline negative associations were seen in inferior frontal gyrus $(p=0.059)$ in the right hemisphere (Figure 1A and eTable 2, links.lww.com/WNL/B612). On post hoc analysis, the perimenopausal and postmenopausal groups had smaller GMV in these regions compared to the premenopausal group $(p \leq 0.033$; Table 2 and Figure 1B). Results remained significant after controlling for hysterectomy status and HT use and after excluding hysterectomized participants $(p<0.05$; Figure 1C).

As shown in Figure 1D, the postmenopausal and perimenopausal groups, and to a lesser extent the premenopausal group, exhibited lower GMV in MTL (including amygdala, hippocampus, parahippocampal gyrus, and entorhinal cortex), fusiform gyrus, and basal ganglia compared to men $(p<$ 0.05; eTable 2, links.lww.com/WNL/B612). In addition, the perimenopausal and postmenopausal groups exhibited lower GMV than men in precuneus, frontal, and temporal regions $(p<0.05$; Figure 1D and eTable 2).

\section{Hysterectomy Status}

There were no significant associations between hysterectomy status and GMV in any region.

\section{Age at Menarche}

There were no significant associations between age at menarche and GMV in any region.

\section{Age at Menopause}

There were no significant associations between age at menopause and GMV in any region.

\section{Reproductive Lifespan}

Positive associations between reproductive span and GMV were observed in a cluster encompassing superior parietal lobule and precuneus of the left hemisphere (cluster extent 129 voxels, $\mathrm{x}=-12, \mathrm{y}=-61, \mathrm{z}=71, z=2.92$, corrected $p=$ 0.025; Figure 2, A and B). Results remained significant after controlling for hysterectomy status and HT use and after excluding hysterectomized participants (Figure 2C). 
Table 1 Participants' Characteristics

\begin{tabular}{|c|c|c|}
\hline & Women & Men \\
\hline No. & 99 & 29 \\
\hline Age (SD), range, y & $52(6), 40-65$ & $52(7), 40-65$ \\
\hline APOE $\varepsilon 4$ status, $\%$ positive & 47 & 47 \\
\hline \multicolumn{3}{|l|}{ Ethnicity, \% } \\
\hline White & 80 & 76 \\
\hline Asian & 6 & 10 \\
\hline Black/African American & 6 & 3 \\
\hline Hispanic & 4 & 7 \\
\hline Mixed & 6 & 4 \\
\hline Education, y & $17(2)$ & $18(2)$ \\
\hline \multicolumn{3}{|l|}{ Smoking status, \% } \\
\hline Never smoker & 80 & 72 \\
\hline Past smoker & 18 & 8 \\
\hline Current smoker & 2 & 0 \\
\hline Hypertension, \% & 7 & 20 \\
\hline Waist to hip ratio & $0.85(0.12)$ & $0.95(0.05)$ \\
\hline Menopause status, \% postmenopausal & 50 & NA \\
\hline Hysterectomy status, $\%$ positive & & NA \\
\hline Full hysterectomy & 6 & \\
\hline Partial hysterectomy & 6 & \\
\hline Oophorectomy only & 1 & \\
\hline Age at menarche (SD), range $(n=88), y$ & $13(1), 10-16$ & NA \\
\hline Age at menopause (SD), range, y & & NA \\
\hline Entire cohort $(n=48)$ & $51(3), 40-58$ & \\
\hline $\begin{array}{l}\text { Nonhysterectomized participants } \\
\quad(n=38)\end{array}$ & $52(3), 47-58$ & \\
\hline Reproductive span (SD), range, y & & NA \\
\hline Entire cohort $(n=47)$ & $39(4), 28-47$ & \\
\hline $\begin{array}{l}\text { Nonhysterectomized participants } \\
\quad(n=37)\end{array}$ & $39(3), 33-47$ & \\
\hline
\end{tabular}

No. of children, $\%(n=96)$

\begin{tabular}{lll}
\hline $\mathbf{0}$ & 21 & 21 \\
\hline $\mathbf{1}$ & 17 & 7 \\
\hline $\mathbf{2}$ & 35 & 45 \\
\hline $\mathbf{3}$ & 27 & 27 \\
\hline HT status, \% & & \\
\hline Never user & & 94 \\
\hline Past user & 69 & 3 \\
\hline Current user & 4 & 3 \\
\hline
\end{tabular}

Table 1 Participants' Characteristics (continued)

\begin{tabular}{lll}
\hline & Women & Men \\
\hline HC status $(\mathbf{n}=98), \%$ & 38 & NA \\
\hline Never user & 53 & \\
\hline Past user & 9 & \\
\hline Current user & & $-0.10(0.15)$ \\
\hline Cognitive measures, mean (SEM) & & $-0.06(0.12)$ \\
\hline Memory scores & $0.03(0.08)$ & \\
\hline Global cognition scores & $-0.01(0.06)$ & \\
\hline
\end{tabular}

Abbreviations: $\mathrm{HC}=$ hormonal contraceptive; $\mathrm{HT}=$ hormonal therapy; $\mathrm{NA}=$ not applicable.

Values are means (SD) unless otherwise specified. In presence of missing data, the sample size is indicated in parentheses.

a Menopause HT for women and testosterone therapy for men.

For every 1-year increase in reproductive span, GMV increased by 0.01 units $(95 \%$ confidence interval $[\mathrm{CI}], 0.00-0.01, p=$ 0.006 ; Table 2). Using dichotomized values and adjusting by age and TIV showed that a reproductive span $\geq 39$ years was associated with 0.05-unit-larger GMV (95\% CI 0.01-0.09) relative to a reproductive span $<39$ years $(p=0.013$; Table 2$)$.

We descriptively examined age at menarche and age at menopause for associations with GMV extracted from the superior parietal and precuneus cluster. Only age at menopause showed significant effects on GMV in the entire postmenopausal sample $(p=0.009)$ and among nonhysterectomized participants $(p=0.013$; eFigure 1$)$.

\section{Number of Children and Pregnancies}

In women, number of children was positively associated with GMV in inferior and middle frontal gyri and middle and inferior temporal gyri $(p \leq 0.021$; Figure $3 \mathrm{~A}$ and eTable 3, links.lww. $\mathrm{com} / \mathrm{WNL} / \mathrm{B} 612)$. In these regions, for every 1 -unit increase in number of children, GMV increased by 0.02 units $(95 \% \mathrm{CI}$ $0.01-0.03, p \leq 0.001$; Table 2 and Figure 3B). Number of pregnancies was also positively associated with GMV in middle temporal gyri $(p<0.05$; Table 2$)$. Results remained significant after controlling for age at firstborn. On post hoc analysis, having $\geq 2$ children was associated with larger GMV in the above frontal and temporal regions compared to having no children $(p \leq$ 0.012 ), whereas no differences were found between the uniparous and nulliparous groups (Table 2).

Among men, there were no significant associations between number of children and GMV. Assessing results at a more liberal $p<0.001$, uncorrected, did not yield significant results.

HT

Positive associations between HT use and GMV were observed in superior frontal gyrus and supramarginal gyrus bilaterally; middle temporal gyrus and frontal pole of the right 
A

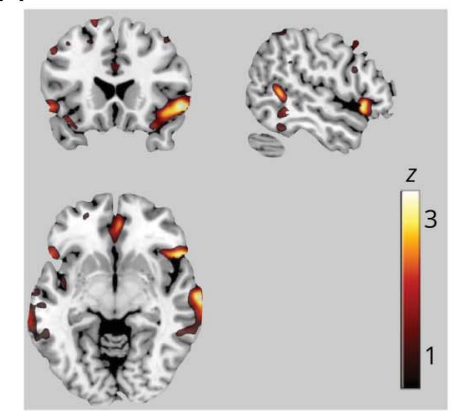

D.a Premenopause vs men
B

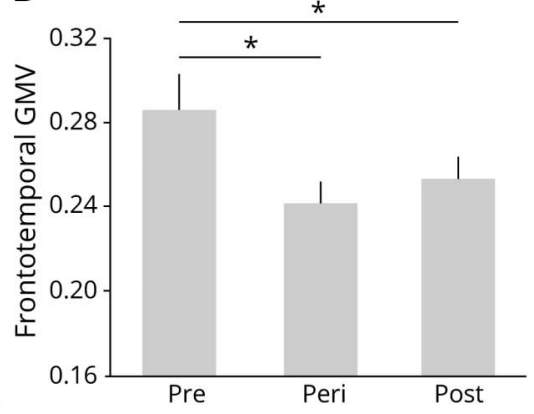

D.b Perimenopause vs men

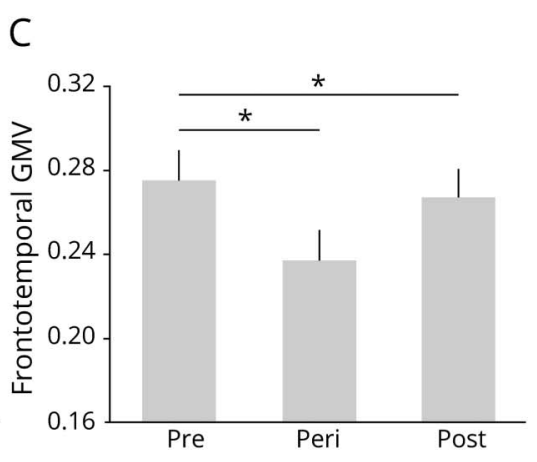

D.c Postmenopause vs men
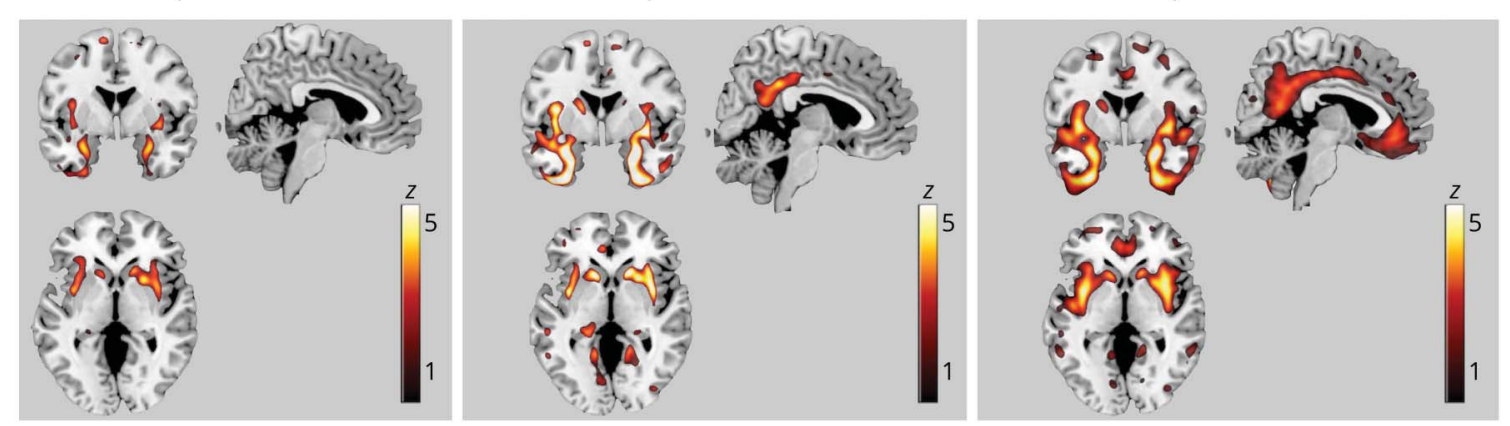

(A) Statistical parametric maps (SPMs) showing negative associations between menopause status and regional gray matter (GM) volume (GMV), adjusted for age and total intracranial volume (TIV). Anatomic location and statistics are reported in eTable 2, links.lww.com/WNL/B612. (B) Plots representing age- and TIV-adjusted mean ( \pm SEM) GMV extracted at the peak of statistical significance, expressed in units of GM density, comparing premenopausal (PRE), perimenopausal (PERI), and postmenopausal (POST) groups in the entire cohort. (C) Plots representing GMV by menopause status among nonhysterectomized participants. (D.a-D.c) SPMs showing GMV differences between each menopausal group and men, adjusted by age and TIV. Anatomic location and statistics are reported in eTable 2. SPMs are superimposed on a standardized MRI and represented on a color-coded scale with corresponding $z$ score values. *Significant at $p<0.05$.

hemisphere; and inferior temporal gyrus, fusiform gyrus, and medial frontal gyrus of the left hemisphere $(p \leq 0.015$; Figure 4A and eTable 4, links.lww.com/WNL/B612). In these regions, HT users had larger GMV compared to never users ( $p=0.001$; Table 2 and Figure 4B). Results remained significant after adjusting by duration of HT use and after excluding hysterectomized participants (Figure 4B).

\section{Hormonal Contraceptives}

Positive associations between HC use and GMV were observed in precuneus, fusiform gyrus, superior parietal lobule, angular gyrus, and inferior frontal gyrus of the left hemisphere and in fusiform gyrus of the right hemisphere $(p \leq 0.005$; Figure 4C and eTable 4, links.lww.com/WNL/B612). Results remained significant after adjusting by duration of $\mathrm{HC}$ use as a covariate. In these regions, past and present users had larger GMV than never users $(p<0.001$; Table 2 and Figure 4D).

Because both HT and HC were positively associated with GMV, we tested for interaction effects of these exposures on GMV at the peak of significance for each contrast: precuneus for HC and superior frontal gyrus for HT. Although the interaction term did not reach significance, participants reporting use of both HC and HT $(n=19)$ showed larger GMV than HC and HT never users $(\mathrm{n}=26)$ in both regions
(12\% and 22\%, respectively, $p \leq 0.027$; eFigure 2, links.lww. com/WNL/B612).

\section{Reproductive History Indicators and Cognition}

There were no significant associations between reproductive history indicators and memory or global cognition scores in women or men (Table 3).

\section{Sensitivity Analysis}

\section{Associations Between Reproductive History Indicators and MTL GMV}

With the VOI approach, in women, MTL GMV was negatively associated with menopause status $(p \leq 0.041)$ and positively associated with $\mathrm{HC}$ use $(p=0.017)$ and number of children ( $p=0.026$; eTable 5, links.lww.com/WNL/B612). For every 1-unit increase in number of children, MTL GMV increased by 0.01 unit ( $95 \%$ CI $0.00-0.01$ ), which was driven by having $\geq 2$ children compared to having no children ( $p=$ 0.028 ; eTable 5). In men, there were no significant associations between number of children and MTL GMV ( $p=$ 0.875).

\section{Associations Between Regional GMV and Cognition}

As shown in eTable 6, links.lww.com/WNL/B612, inferior temporal and MTL GMVs were positively associated with 
Table 2 Associations Between Female Reproductive History Indicators and GMV

\begin{tabular}{|c|c|c|c|c|c|c|c|c|}
\hline & \multicolumn{4}{|l|}{ Model 1} & \multicolumn{4}{|l|}{ Model 2} \\
\hline & Coefficient & $95 \% \mathrm{Cl}$ & $p$ Value & $R^{2}$ value & Coefficient & $95 \% \mathrm{Cl}$ & $p$ Value & $R^{2}$ value \\
\hline \multicolumn{9}{|l|}{ Menopause status } \\
\hline Premenopause & \multicolumn{3}{|l|}{ Ref } & 0.315 & \multicolumn{3}{|l|}{ Ref } & \multirow[t]{3}{*}{0.339} \\
\hline Perimenopause & -0.04 & $-0.07,0.02$ & 0.033 & & -0.06 & $-0.09,-0.02$ & 0.006 & \\
\hline Postmenopause & -0.06 & $-0.11,-0.01$ & 0.014 & & -0.08 & $-0.13,-0.03$ & 0.003 & \\
\hline \multicolumn{9}{|l|}{ Reproductive span } \\
\hline Numeric & 0.01 & $0.00,0.01$ & 0.006 & 0.174 & 0.01 & $0.00,0.01$ & 0.041 & 0.304 \\
\hline$<39 y$ & \multicolumn{3}{|l|}{ Ref } & 0.146 & \multicolumn{3}{|l|}{ Ref } & \multirow[t]{2}{*}{0.296} \\
\hline$\geq 39 y$ & 0.05 & $0.01,0.09$ & 0.013 & & 0.04 & $0.00,0.08$ & 0.051 & \\
\hline \multicolumn{9}{|l|}{ No. of children } \\
\hline Numeric & 0.02 & $0.01,0.03$ & $<0.001$ & 0.358 & 0.03 & $0.01,0.04$ & $<0.001$ & 0.413 \\
\hline 0 & \multicolumn{3}{|l|}{ Ref } & 0.342 & \multicolumn{3}{|l|}{ Ref } & \multirow[t]{3}{*}{0.380} \\
\hline 1 & 0.00 & $-0.04,0.04$ & 0.873 & & 0.00 & $-0.04,0.05$ & 0.940 & \\
\hline$\geq 2$ & 0.04 & $0.01,0.07$ & 0.012 & & 0.05 & $0.02,0.09$ & 0.003 & \\
\hline No. of pregnancies & 0.01 & $0.00,0.02$ & 0.028 & 0.298 & 0.01 & $0.00,0.02$ & 0.018 & 0.323 \\
\hline HT use & 0.05 & $0.02,0.08$ & 0.001 & 0.200 & 0.05 & $0.02,0.08$ & 0.003 & 0.214 \\
\hline HC use & 0.06 & $0.03,0.09$ & $<0.001$ & 0.317 & 0.06 & $0.03,0.09$ & $<0.001$ & 0.278 \\
\hline \multicolumn{9}{|c|}{$\begin{array}{l}\text { Abbreviations: } \mathrm{Cl}=\text { confidence interval; } \mathrm{GMV}=\text { gray matter volume; } \mathrm{HC}=\text { hormonal contraceptives; } \mathrm{HT}=\text { menopause hormone therapy; Ref }=\text { referent. } \\
\text { Model 1: adjusted for age and intracranial volume; model } 2 \text { : adjusted for age, intracranial volume, } A P O E \text { \& } 4 \text { status, and midlife health variables. GMV measures } \\
\text { are extracted from the peak association cluster for each exposure, e.g., inferior temporal gyrus for menopause status, precuneus for reproductive span and } \\
\text { HC use, inferior frontal gyrus for number of children, and superior frontal gyrus for HT use (eTables 2-4, links. Iww.com/WNL/B612). }\end{array}$} \\
\hline
\end{tabular}

memory scores $(p \leq 0.034)$. MTL GMV was also positively associated with global cognition scores $(p=0.018)$.

\section{Discussion}

In a cohort of well-characterized midlife women at risk for $\mathrm{AD}$, with the use of voxel-based morphometry and VOI analysis, some reproductive history indicators signaling longer estrogen exposure were associated with larger MRI-derived GMV in brain regions vulnerable to cognitive aging and $\mathrm{AD}$. These indicators included premenopausal status, a longer reproductive span, higher number of children and pregnancies, and use of HT and HC. Results were independent of age, APOE $\varepsilon 4$ status, midlife health indicators, and exposure-specific confounders.

These results are in line with preclinical work indicating neuroprotective effects of estrogen in women ${ }^{8,9}$ and provide neurophysiologic correlates to epidemiologic evidence of associations between indices of prolonged estrogen exposure and lower risk of dementia or cognitive decline. ${ }^{10-13}$

Multiple lines of work identify endocrine aging as a driver of brain aging and $\mathrm{AD}$ risk in women, ${ }^{2,8,9}$ with menopause marking a dramatic decline in estrogen production along with onset of multiple physical and cognitive symptoms quite distinct from the gradual tapering of testosterone in male andropause. ${ }^{8,9}$ Estrogen, especially $17 \beta$-estradiol, has been shown to promote neuronal resilience by reducing inflammation, tau hyperphosphorylation, and $\beta$-amyloid $(\mathrm{A} \beta)$-induced neurotoxicity, whereas estrogen deprivation after menopause has been linked to increased neuronal aging and $\mathrm{AD}$ risk. ${ }^{8,9}$ We previously reported that women undergoing the menopause transition exhibit reduced GMV, as well as brain hypometabolism and higher $\mathrm{A} \beta$ burden, compared to premenopausal women and to age-controlled men. ${ }^{4-7}$ Present findings confirm associations between the menopause transition and presence of lower GMV in cortical and subcortical regions vulnerable to aging and $\mathrm{AD}$, and expand on prior work by identifying reproductive history factors that are positively associated with GMV, and may thus offset the impact of menopause on brain aging.

Among endogenous exposures, a longer reproductive span was associated with larger superior parietal and precuneus GMV independent of age, hysterectomy status, and HT use. A later age at menopause also correlated with GMV in these regions, whereas age at menarche did not. These data are 
A

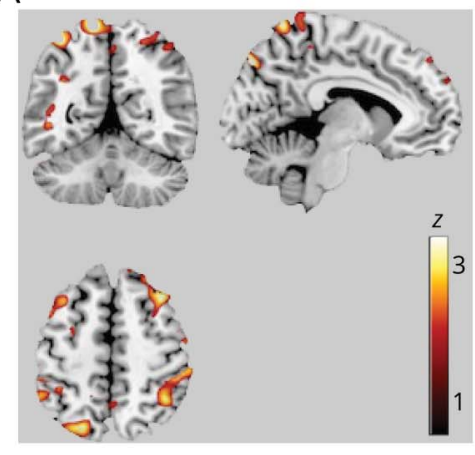

B

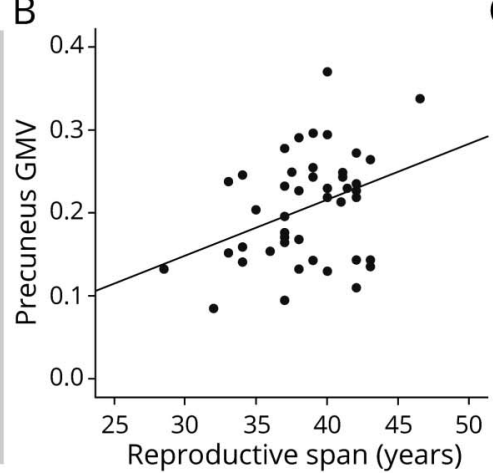

C

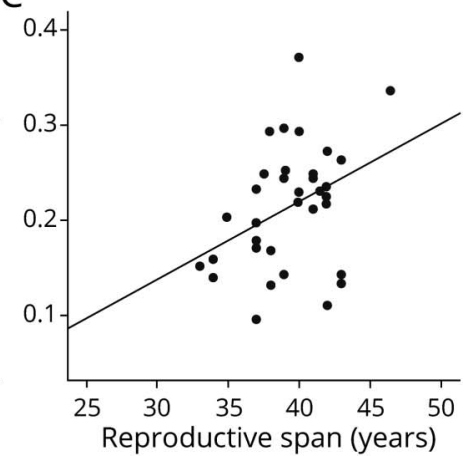

(A) Statistical parametric maps (SPMs) showing positive associations between reproductive span years and regional gray matter volume (GMV) at $p<0.05$, cluster level corrected, adjusted for age and total intracranial volume. SPMs are superimposed on a standardized MRI and represented on a color-coded scale with corresponding $z$ score values. (B) Plots depicting correlations between reproductive years and GMV extracted at the peak of statistical significance in the entire cohort and (C) among nonhysterectomized participants.

consistent with prior work demonstrating positive associations between reproductive span, especially in the presence of older age at menopause, and risk of dementia or cognitive decline. ${ }^{10-}$ ${ }^{13}$ However, other studies reported increased dementia risk with longer reproductive spans and older age at menopause $\mathrm{e}^{15,16}$ or no associations. ${ }^{12,18}$ Negative studies generally focused on older postmenopausal women, ${ }^{15,16}$ excluded those with hysterectomy/oophorectomy, ${ }^{15,16}$ and in some cases did not assess HT or HC exposure ${ }^{16}$ or reported effects only in APOE $\varepsilon 4$ carriers, ${ }^{16}$ which could account for the mixed findings. Our study differs from these reports in 3 main respects: it focuses on midlife women, includes information on all relevant variables, and uses neuroimaging measures instead of dementia incidence as the primary endpoint. The presymptomatic phase of $\mathrm{AD}$ corresponds with midlife years, ${ }^{3}$ during which estrogen levels in women begin to decline. Because estrogen exposures occur before or concomitant with menopause, our approach enables closer examination of the impact of reproductive factors on the brain while avoiding possible effects of attrition, recall, and survival bias. In fact, our results are consistent with epidemiologic studies examining younger women with a narrower window of age at menopause. ${ }^{10,11}$

Number of children and number of pregnancies were also associated with larger GMV in frontal and temporal regions of midlife women, whereas no associations were observed among men. This is consistent with epidemiologic reports indicating a lower risk of cognitive decline or $\mathrm{AD}$ for older parous compared to nulliparous women, ${ }^{11,29}$ although results are mixed. ${ }^{14,19,20}$ The largest epidemiologic study to date showed no long-term influence of pregnancy history on agerelated cognitive function. ${ }^{30}$ Contrasting results between imaging and clinical studies might be in part due to the timing of the observations; the effects of motherhood on the brain are likely more discernible in midlife, thus closer in time to childbirth, than in older age or at postmortem. Imaging studies of new mothers have consistently reported beneficial effects of pregnancy and childbirth on brain structure and function. ${ }^{31}$ Pregnancy entails higher levels of estrogens, which may have beneficial effects in terms of cumulative estrogen

Figure 3 Associations Between Number of Children and GMV

A

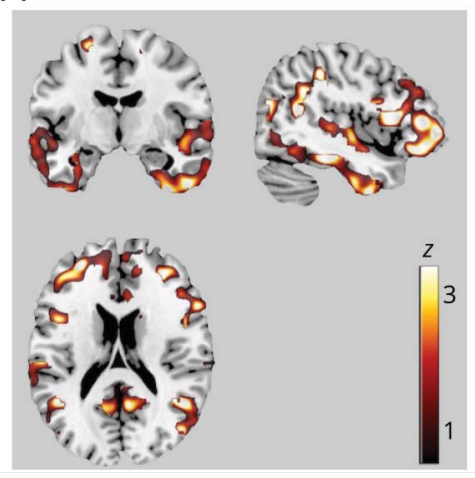

B

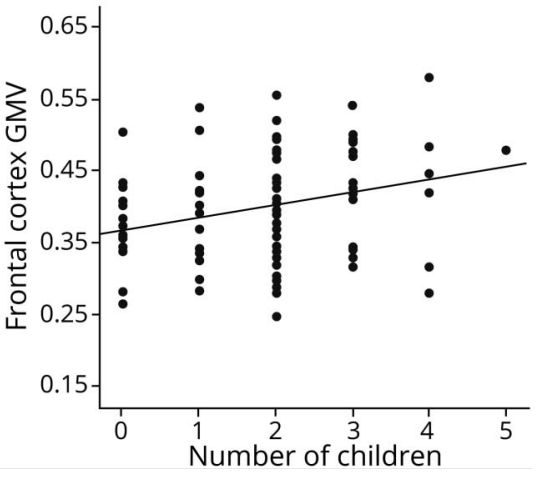

(A) Statistical parametric maps (SPMs) showing positive associations between number of children and regional gray matter volume (GMV) at $p<0.05$, cluster level corrected, adjusted for age and total intracranial volume. SPMs are superimposed on a standardized MRI and represented on a color-coded scale with corresponding $z$ score values. Anatomic location and statistics are reported in eTable 3, links.lww.com/WNL/B612. See legend for Figure $1 \mathrm{~B}$ for plots depicting associations between number of children and GMV. 
A

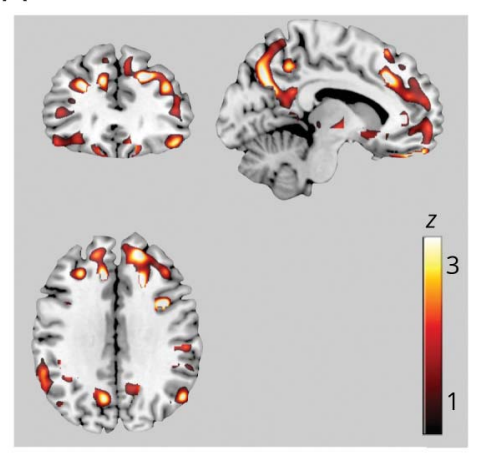

C

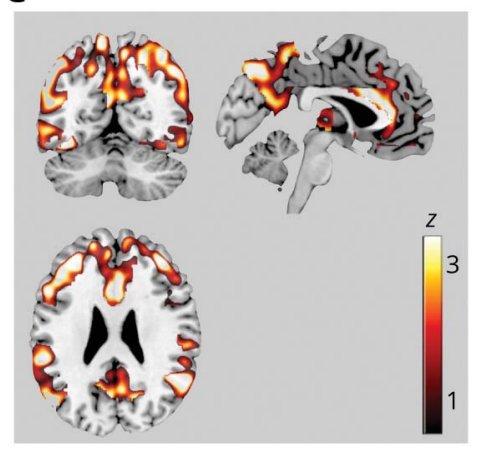

B

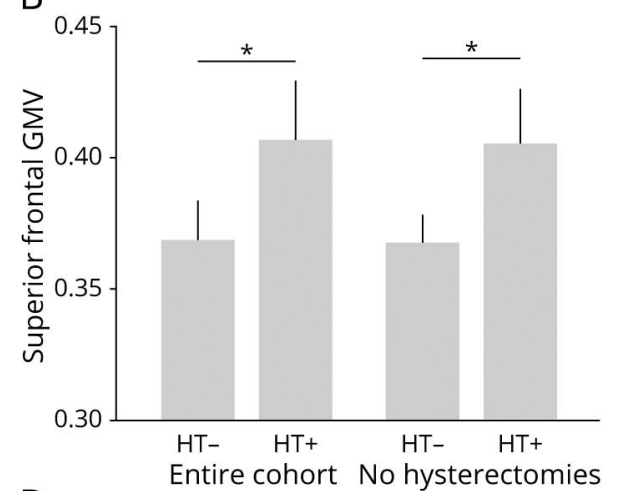

D

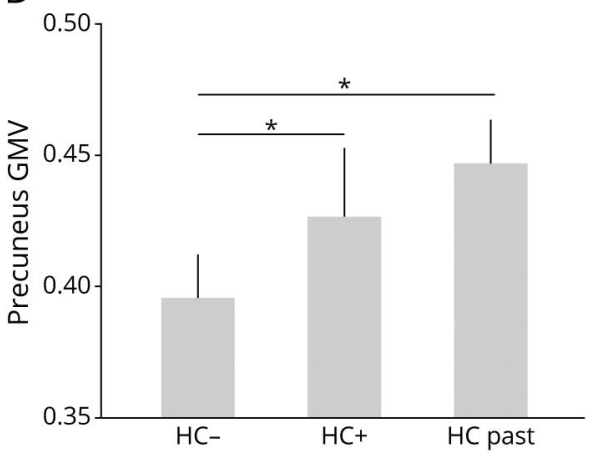

Statistical parametric maps (SPMs) showing positive associations between (A) menopause hormonal therapy (HT) and gray matter volume (GMV) and (C) hormonal contraceptive (HC) use and GMV, at $p<$ 0.05 , cluster level corrected, adjusted for age and total intracranial volume (TIV). SPMs are superimposed on a standardized MRI and represented on a color-coded scale with corresponding $z$ score values. Anatomic location and statistics are reported in eTable 4, links. IwW.com/WNL/B612. Plots representing age- and TIVadjusted mean (+SEM) GMV extracted at the peak of statistical significance, comparing (B) HT users (HT+) and never users (HT-) in the entire cohort and among nonhysterectomized participants and (D) HC current users $(\mathrm{HC}+)$, past users (HC-past), and never users $(\mathrm{HC}-) .{ }^{\star} p<0.05$. exposure throughout a woman's life. While circulating estrogen concentrations tend to be lower in parous compared to nulliparous women, ${ }^{20}$ parity seems to render the brain more responsive to estrogen later in life, ${ }^{32}$ which might contribute to favorable brain aging trajectories.

For exogeneous estrogen exposures, we observed positive effects of both HT and HC on GMV in several regions. This finding is consistent with observational studies reporting a protective effect of $\mathrm{HT}$ on cognitive aging and $\mathrm{AD}$ risk, ${ }^{33-35}$ especially among younger (50-59 years) women, ${ }^{36}$ and with neuroimaging studies indicating enhancing effects of HT on brain structure and function. ${ }^{37}$ On the other hand, clinical trials reported increased dementia risk among postmenopausal women $\geq 65$ years of age treated with estrogenplus-progestin $\mathrm{HT}^{38}$ and no effects with estrogen-alone $\mathrm{HT},{ }^{39}$ while recent studies of early postmenopausal women showed no effects of HT on cognition. ${ }^{40,41}$ Currently, the efficacy of HT is thought to depend on timing of treatment with respect to age at menopause, with benefits pertaining to early initiation. ${ }^{21,22}$ Our findings that HT use in midlife is associated with larger GMV support evidence that HT near the time of menopause, as opposed to later in life, may support brain aging.

Positive effects of HC use on GMV are consistent with imaging observations that $\mathrm{HC}$ users in their 20s exhibited larger regional GMV compared to nonusers in some of the same cortical regions identified in the present study. ${ }^{42-44}$ However, the long-term effects of $\mathrm{HC}$ on brain and cognition have seldom been investigated. To the best of our knowledge, the only study that looked at $\mathrm{HC}$ in relation to $\mathrm{AD}$ risk reported no associations between $\mathrm{HC}$ use and incidence of dementia. ${ }^{15}$ Because $\mathrm{HC}$ use typically ends with menopause, it is possible that its effects wane after the end of exposure. Nonetheless, in our cohort, middle-aged women who took HC during their reproductive years and later took $\mathrm{HT}$ for menopause had larger regional GMV compared to never users of both, which warrants further investigation.

While reproductive history indicators were not directly associated with cognitive performance, GMV in temporal clusters positively correlated with memory and global cognition, suggesting possible mediation effects. In fact, while selfreports of poor memory and concentration are common in women undergoing the menopause transition, ${ }^{45}$ menopause itself has not been associated with functional impairment or deficits on cognitive testing. ${ }^{21,22,26}$ It is possible that the protective reproductive history factors identified here may offset the neurologic effects of the menopause transition and help explain the lack of cognitive impairment after menopause. $^{26}$ Nonetheless, while we focused on cognitive tests known to be sensitive to estrogen changes, it is possible that different tests might yield different results. Because our sample was highly educated, results may not apply to women of diverse educational status. Longitudinal studies are warranted 
Table 3 Associations Between Reproductive History Indicators and Cognition

\begin{tabular}{|c|c|c|c|c|c|c|c|c|}
\hline & \multicolumn{4}{|l|}{ Memory } & \multicolumn{4}{|c|}{ Global cognition } \\
\hline & Coefficient & $95 \% \mathrm{Cl}$ & $p$ Value & $R^{2}$ value & Coefficient & $95 \% \mathrm{Cl}$ & $p$ Value & $R^{2}$ value \\
\hline \multicolumn{9}{|l|}{ Menopause status } \\
\hline Premenopause & Ref & & & 0.042 & Ref & & & 0.031 \\
\hline Perimenopause & -0.12 & $-0.67,0.42$ & 0.815 & & -0.15 & $-0.49,0.19$ & 0.697 & \\
\hline Postmenopause & 0.13 & $-0.60,0.86$ & 0.820 & & -0.23 & $-0.71,0.25$ & 0.697 & \\
\hline \multicolumn{9}{|l|}{ Age at menarche } \\
\hline Numeric & 0.01 & $-0.12,0.14$ & 0.918 & 0.022 & 0.02 & $-0.07,0.10$ & 0.803 & 0.032 \\
\hline$<13 y$ & Ref & & & 0.022 & Ref & & & 0.032 \\
\hline$\geq 13 y$ & -0.02 & $-0.38,0.34$ & 0.918 & & 0.04 & $-0.18,0.26$ & 0.803 & \\
\hline \multicolumn{9}{|l|}{ Age at menopause } \\
\hline Numeric & -0.06 & $-0.13,0.02$ & 0.264 & 0.101 & -0.05 & $-0.10,0.02$ & 0.275 & 0.088 \\
\hline$<51$ y & Ref & & & 0.082 & Ref & & & 0.117 \\
\hline$\geq 51 \mathrm{y}$ & -0.39 & $-0.90,0.12$ & 0.264 & & -0.38 & $-0.72,0.04$ & 0.261 & \\
\hline \multicolumn{9}{|l|}{ Reproductive span } \\
\hline Numeric & -0.07 & $-0.14,0.01$ & 0.261 & 0.101 & -0.06 & $-0.11,-0.02$ & 0.198 & 0.158 \\
\hline$<39 y$ & Ref & & & 0.098 & Ref & & & 0.091 \\
\hline$\geq 39 y$ & -0.42 & $-0.91,0.06$ & 0.261 & & -0.32 & $-0.65,0.01$ & 0.275 & \\
\hline Hysterectomy status & -0.12 & $-0.63,0.40$ & 0.815 & 0.033 & -0.08 & $-0.42,0.26$ & 0.803 & 0.025 \\
\hline HT use & -0.22 & $-0.60,0.16$ & 0.452 & 0.044 & -0.12 & $-0.36,0.12$ & 0.697 & 0.031 \\
\hline HC use & 0.31 & $-0.04,0.66$ & 0.261 & 0.064 & 0.09 & $-0.13,0.3$ & 0.697 & 0.027 \\
\hline No. of pregnancies & 0.09 & $0.01,0.18$ & 0.210 & 0.072 & 0.04 & $-0.02,0.09$ & 0.580 & 0.025 \\
\hline \multicolumn{9}{|c|}{ No. of children (women) } \\
\hline Numeric & 0.11 & $-0.03,0.25$ & 0.338 & 0.050 & 0.02 & $-0.07,0.11$ & 0.803 & 0.003 \\
\hline 0 & Ref & & & 0.095 & & & & 0.009 \\
\hline 1 & 0.585 & $0.04,1.13$ & 0.210 & & 0.098 & $-0.25,0.45$ & 0.803 & \\
\hline$\geq 2$ & 0.540 & $0.12,0.96$ & 0.210 & & 0.127 & $-0.15,0.41$ & 0.697 & \\
\hline \multicolumn{9}{|l|}{ No. of children (men) } \\
\hline Numeric & -0.06 & $-0.34,0.22$ & 0.815 & 0.012 & 0.00 & $-0.19,0.19$ & 0.976 & 0.012 \\
\hline 0 & Ref & & & 0.044 & Ref & & & 0.057 \\
\hline 1 & -0.687 & $-2.08,0.71$ & 0.524 & & -0.48 & $-1.41,0.47$ & 0.697 & \\
\hline$\geq 2$ & -0.162 & $-0.96,0.64$ & 0.815 & & -0.07 & $-0.61,0.48$ & 0.845 & \\
\hline
\end{tabular}

Abbreviations: $\mathrm{Cl}$ = confidence interval; $\mathrm{HC}=$ hormonal contraceptives; $\mathrm{HT}=$ menopause hormone therapy; Ref = referent.

Results are adjusted by age.

to assess whether brain and cognitive aging trajectories differ as a function of reproductive history and $\mathrm{AD}$ predisposition.

This study has multiple strengths. First, we examined several reproductive history indicators, which independently and in combination may serve as proxies for estrogen exposures that occur throughout the life course. Second, we examined a large sample of well-characterized middle-aged women with simultaneous brain MRI scans, cognitive assessments, and health, including medical history and APOE $\varepsilon 4$ status for all participants. In addition, we collected data on HT and HC, including duration of use, and number of pregnancies and 
children, with a male comparison group, and age at first birth. Another strength is the multivariable approach, which enabled examination of the confounding and interacting roles of different exposures on outcome measures.

We were unable to assess the accuracy of self-reported age at menarche. While prior work has shown moderate to high correlations between repeated measures of self-reported age at menarche, ${ }^{46}$ more work is needed to confirm lack of associations between age at menarche and GMV. We are confident about the accuracy of self-reported age at menopause because the majority of our postmenopausal participants were within 10 years of their menopause diagnosis, which was clinician-confirmed in many cases.

Prior work indicates that induced menopause influences dementia risk, especially that due to bilateral oophorectomy, with younger age associated with greater risk of dementia and higher neuropathology burden. ${ }^{47,48}$ Because only $7 \%$ of our participants had oophorectomies, we were likely underpowered to detect significant effects. While we included only participants who had surgery before menopause, we did not have precise information on the timing of surgery, which may also lead to underestimation of possible associations.

MRI-derived GMV measures are sensitive to neuronal aging and to early $\mathrm{AD}$-related neurodegeneration. ${ }^{23}$ However, because these measures are not specific to $\mathrm{AD}$, caution is required in interpreting these results as related to $\mathrm{AD}$ risk. Longitudinal studies and analysis of $A \beta$ and tau markers are needed to examine the predictive value of the observed associations. In addition, more work is needed to elucidate the biological pathways by which different estrogen-associated processes affect brain aging and $\mathrm{AD}$ risk and to test for anatomic interactions among exposures' effects.

Because all our participants were cognitively normal and 40 to 65 years of age, few would have had substantial neuropathologic burden, ${ }^{3}$ making this cohort an ideal population for identification of early risk markers and testing of preventive strategies. It is important to note that some of the reproductive factors showing associations with GMV are potentially modifiable, and targeted risk factor modification has shown promise in real-world clinical settings. ${ }^{49}$ For example, while age at menopause is in part genetically linked, lifestyle and environmental factors also play a role. ${ }^{45}$

We caution that the present results were found in healthy, welleducated, carefully screened research participants, including mostly White people of generally middle/high socioeconomic status, which limits the generalizability of our findings. No studies have yet been conducted to investigate reproductive history effects on $\mathrm{AD}$ biomarkers based on ethnicity. Clinical evidence of higher frequency and severity of menopausal symptoms in Black and Hispanic women ${ }^{50}$ strongly argues for examination of outcomes across ethnic groups. Another limitation is our inability to generalize to gender-diverse patient populations and to those taking gender-affirming HT.

Overall, our brain imaging findings identify reproductive history events associated with GMV vulnerability (the menopause transition) and resilience (longer reproductive span, number of children, HT and HC use) in midlife women. Understanding sex-specific biological pathways through which reproductive history modulates brain aging is crucial to inform preventive efforts and therapeutic development.

\section{Study Funding}

Funding provided by the NIH/National Institute on Aging (P01AG026572, R01AG057931, R01AG035137), NIH/ National Center for Advancing Translational Sciences UL1TR002384, the Cure Alzheimer's Fund, and Maria Shriver's Women's Alzheimer's Movement, as well as the generous support of Harold W.McGraw III and Nancy G. McGraw and of Carol and Michael Weisman.

\section{Disclosure}

The authors report no disclosures relevant to the manuscript. Go to Neurology.org/N for full disclosures.

\section{Publication History}

Received by Neurology April 13, 2021. Accepted in final form September 22, 2021.

\begin{tabular}{|c|c|c|}
\hline Name & Location & Contribution \\
\hline $\begin{array}{l}\text { Eva } \\
\text { Schelbaum, } \\
\text { BA }\end{array}$ & $\begin{array}{l}\text { Weill Cornell } \\
\text { Medicine, New } \\
\text { York, NY }\end{array}$ & $\begin{array}{l}\text { Major role in data acquisition, } \\
\text { obtained the official approvals, data } \\
\text { management, interpreted the data, } \\
\text { drafted the manuscript }\end{array}$ \\
\hline $\begin{array}{l}\text { Lacey } \\
\text { Loughlin, BA }\end{array}$ & $\begin{array}{l}\text { Weill Cornell } \\
\text { Medicine, New } \\
\text { York, NY }\end{array}$ & $\begin{array}{l}\text { Major role in data acquisition, } \\
\text { obtained the official approvals, data } \\
\text { management, interpreted the data, } \\
\text { drafted the manuscript }\end{array}$ \\
\hline $\begin{array}{l}\text { Steven Jett, } \\
\text { MA }\end{array}$ & $\begin{array}{l}\text { Weill Cornell } \\
\text { Medicine, New } \\
\text { York, NY }\end{array}$ & $\begin{array}{l}\text { Major role in data acquisition, } \\
\text { obtained the official approvals, data } \\
\text { management, reviewed the } \\
\text { manuscript for intellectual content }\end{array}$ \\
\hline $\begin{array}{l}\text { Cenai Zhang, } \\
\text { MS }\end{array}$ & $\begin{array}{l}\text { Weill Cornell } \\
\text { Medicine, New } \\
\text { York, NY }\end{array}$ & $\begin{array}{l}\text { Major role in data acquisition, } \\
\text { obtained the official approvals, data } \\
\text { management and statistical analysis, } \\
\text { interpreted the data, drafted the } \\
\text { manuscript }\end{array}$ \\
\hline $\begin{array}{l}\text { Grace Jang, } \\
\text { BA }\end{array}$ & $\begin{array}{l}\text { Weill Cornell } \\
\text { Medicine, New } \\
\text { York, NY }\end{array}$ & $\begin{array}{l}\text { Major role in data acquisition, } \\
\text { obtained the official approvals, data } \\
\text { management, reviewed the } \\
\text { manuscript for intellectual content }\end{array}$ \\
\hline $\begin{array}{l}\text { Niharika } \\
\text { Malviya, BA }\end{array}$ & $\begin{array}{l}\text { Weill Cornell } \\
\text { Medicine, New } \\
\text { York, NY }\end{array}$ & $\begin{array}{l}\text { Major role in data acquisition, } \\
\text { obtained the official approvals, data } \\
\text { management, reviewed the } \\
\text { manuscript for intellectual content }\end{array}$ \\
\hline $\begin{array}{l}\text { Hollie } \\
\text { Hristov, NP }\end{array}$ & $\begin{array}{l}\text { Weill Cornell } \\
\text { Medicine, New } \\
\text { York, NY }\end{array}$ & $\begin{array}{l}\text { Major role in data acquisition, } \\
\text { reviewed the manuscript for } \\
\text { intellectual content }\end{array}$ \\
\hline
\end{tabular}


Appendix (continued)

\begin{tabular}{lll}
\hline Name & Location & Contribution \\
\hline $\begin{array}{l}\text { Silky } \\
\text { Pahlajani, } \\
\text { MD }\end{array}$ & $\begin{array}{l}\text { Weill Cornell } \\
\text { Medicine, New } \\
\text { York, NY }\end{array}$ & $\begin{array}{l}\text { Major role in data acquisition, } \\
\text { reviewed the manuscript for } \\
\text { intellectual content }\end{array}$ \\
\hline $\begin{array}{l}\text { Richard } \\
\text { Isaacson, MD }\end{array}$ & $\begin{array}{l}\text { Weill Cornell } \\
\text { Medicine, New } \\
\text { York, NY }\end{array}$ & $\begin{array}{l}\text { Major role in data acquisition, } \\
\text { reviewed the manuscript for } \\
\text { intellectual content }\end{array}$ \\
\hline $\begin{array}{l}\text { Jonathan P. } \\
\text { Dyke, PhD }\end{array}$ & $\begin{array}{l}\text { Weill Cornell } \\
\text { Medicine, New }\end{array}$ & $\begin{array}{l}\text { Major role in data acquisition, image } \\
\text { data processing, reviewed the } \\
\text { manuscript for intellectual content }\end{array}$ \\
\hline $\begin{array}{l}\text { Hooman } \\
\text { Kamel, MD }\end{array}$ & $\begin{array}{l}\text { Weill Cornell } \\
\text { Medicine, New } \\
\text { York, NY }\end{array}$ & $\begin{array}{l}\text { Procured funding, reviewed the } \\
\text { manuscript for intellectual content }\end{array}$ \\
\hline $\begin{array}{l}\text { Roberta Diaz } \\
\text { Brinton, PhD }\end{array}$ & $\begin{array}{l}\text { University of } \\
\text { Arizona, Tucson }\end{array}$ & $\begin{array}{l}\text { Procured funding, reviewed the } \\
\text { manuscript for intellectual content }\end{array}$ \\
\hline $\begin{array}{l}\text { Lisa Mosconi, } \\
\text { PhD }\end{array}$ & $\begin{array}{l}\text { Weill Cornell } \\
\text { Medicine, New } \\
\text { York, NY }\end{array}$ & $\begin{array}{l}\text { Designed and conceptualized study, } \\
\text { image data processing, interpreted } \\
\text { the data, drafted and revised the } \\
\text { manuscript for intellectual contents, } \\
\text { procured funding }\end{array}$ \\
\hline
\end{tabular}

\section{References}

1. Ferretti MT, Iulita MF, Cavedo E, et al. Sex differences in Alzheimer disease: the gateway to precision medicine. Nat Rev Neurol. 2018;14(8):457-469.

2. Rahman A, Jackson H, Hristov H, et al. Sex and gender driven modifiers of Alzheimer's: the role for estrogenic control across age, race, medical, and lifestyle risks. Front Aging Neurosci. 2019;11:315.

3. Sperling RA, Karlawish J, Johnson KA. Preclinical Alzheimer disease: the challenges ahead. Nat Rev Neurol. 2013;9(1):54-58.

4. Mosconi L, Rahman A, Diaz I, et al. Increased Alzheimer's risk during the menopause transition: a 3-year longitudinal study. PLoS One. 2018;13(12):e0207885.

5. Mosconi L, Berti V, Quinn C, et al. Sex differences in Alzheimer risk: brain imaging of endocrine vs chronologic aging. Neurology. 2017;89(13):1382-1390.

6. Rahman A, Schelbaum E, Hoffman K, et al. Sex-driven modifiers of Alzheimer risk Neurology. 2020;95(2):e166.

7. Mosconi L, Berti V, Dyke J, et al. Menopause impacts human brain structure, connectivity, energy metabolism, and amyloid-beta deposition. Sci Rep. 2021;11(1): 10867.

8. Brinton RD, Yao J, Yin F, Mack WJ, Cadenas E. Perimenopause as a neurological transition state. Nat Rev Endocrinol. 2015;11(7):393-405.

9. Morrison JH, Brinton RD, Schmidt PJ, Gore AC. Estrogen, menopause, and the aging brain: how basic neuroscience can inform hormone therapy in women. J Neurosci. 2006;26(41):10332-10348.

10. Gilsanz P, Lee C, Corrada MM, Kawas CH, Quesenberry CP Jr, Whitmer RA Reproductive period and risk of dementia in a diverse cohort of health care members. Neurology. 2019;92(17):e2005-e2014

11. Fox M, Berzuini C, Knapp LA. Cumulative estrogen exposure, number of menstrual cycles, and Alzheimer's risk in a cohort of British women. Psychoneuroendocrinology. 2013;38(12):2973-2982

12. Georgakis MK, Kalogirou EI, Diamantaras AA, et al. Age at menopause and duration of reproductive period in association with dementia and cognitive function: a systematic review and meta-analysis. Psychoneuroendocrinology. 2016;73:224-243.

13. Rasgon NL, Magnusson C, Johansson AL, Pedersen NL, Elman S, Gatz M. Endogenous and exogenous hormone exposure and risk of cognitive impairment in Swedish twins: a preliminary study. Psychoneuroendocrinology. 2005;30(6):558-567.

14. Sobow T, Kloszewska I. Parity, number of pregnancies, and the age of onset of Alzheimer's disease. J Neuropsychiatry Clin Neurosci. 2004;16(1):120-121.

15. Najar J, Östling S, Waern M, et al. Reproductive period and dementia: a 44-year longitudinal population study of Swedish women. Alzheimers Dement. 2020;16(8): 1153-1163.

16. Geerlings MI, Ruitenberg A, Witteman JC, et al. Reproductive period and risk of dementia in postmenopausal women. JAMA. 2001;285(11):1475-1481.

17. Bertram L, Tanzi RE. Thirty years of Alzheimer's disease genetics: the implications of systematic meta-analyses. Nat Rev Neurosci. 2008;9(10):768-778.

18. Prince MJ, Acosta D, Guerra M, et al. Reproductive period, endogenous estrogen exposure and dementia incidence among women in Latin America and China; A 10/ 66 population-based cohort study. PLoS One. 2018;13(2):e0192889.
19. Colucci M, Cammarata S, Assini A, et al. The number of pregnancies is a risk factor for Alzheimer's disease. Eur J Neurol. 2006;13(12):1374-1377.

20. Beeri MS, Rapp M, Schmeidler J, et al. Number of children is associated with neuropathology of Alzheimer's disease in women. Neurobiol Aging. 2009;30(8) 1184-1191.

21. Maki PM. The timing of estrogen therapy after ovariectomy: implications for neurocognitive function. Nat Clin Pract Endocrinol Metab. 2008;4(9):494-495.

22. Lobo RA. Hormone-replacement therapy: current thinking. Nat Rev Endocrinol. 2017; 13(4):220-231.

23. Jack CR Jr, Knopman DS, Jagust WJ, et al. Update on hypothetical model of Alzheimer's disease biomarkers. Lancet Neurol. 2013;12(2):207.

24. Harlow SD, Gass M, Hall JE, et al. Executive summary of the Stages of Reproductive Aging Workshop + 10: addressing the unfinished agenda of staging reproductive aging. Menopause. 2012;19(4):387-395.

25. Heinemann LA, Saad F, Zimmermann T, et al. The Aging Males' Symptoms (AMS) scale: update and compilation of international versions. Health Qual Life Outcomes. 2003;1:15.

26. Maki PM, Henderson VW. Cognition and the menopause transition. Menopause. 2016;23(7):803-805

27. Ashburner J, Friston KJ. Voxel-based morphometry: the methods. NeuroImage. 2000 $11(6$ pt 1):805-821.

28. Mosconi L, Tsui WH, De Santi S, et al. Reduced hippocampal metabolism in MCI and AD: automated FDG-PET image analysis. Neurology. 2005;64(11):1860-1867.

29. Henderson VW, Guthrie JR, Dudley EC, Burger HG, Dennerstein L. Estrogen exposures and memory at midlife: a population-based study of women. Neurology. 2003; 60(8):1369-1371.

30. Ilango SD, McEvoy LK, Laughlin GA, Bergstrom J, Barrett-Connor E, Kritz-Silverstein D. Pregnancy history and cognitive aging among older women: the Rancho Bernardo Study. Menopause. 2019;26(7):750-757.

31. Brunton PJ, Russell JA. The expectant brain: adapting for motherhood. Nat Rev Neurosci. 2008;9(1):11-25.

32. Barha CK, Galea LA. Motherhood alters the cellular response to estrogens in the hippocampus later in life. Neurobiol Aging. 2011;32(11):2091-2095.

33. Kawas C, Resnick S, Morrison A, et al. A prospective study of estrogen replacement therapy and the risk of developing Alzheimer's disease: the Baltimore Longitudinal Study of Aging. Neurology. 1997;48(6):1517-1521.

34. Paganini-Hill A, Corrada MM, Kawas CH. Increased longevity in older users of postmenopausal estrogen therapy: the Leisure World Cohort Study. Menopause. 2006;13(1):12-18

35. Whitmer RA, Quesenberry CP, Zhou J, Yaffe K. Timing of hormone therapy and dementia: the critical window theory revisited. Ann Neurol. 2011;69(1):163-169.

36. LeBlanc ES, Janowsky J, Chan BK, Nelson HD. Hormone replacement therapy and cognition: systematic review and meta-analysis. JAMA. 2001;285(11):1489-1499.

37. Comasco E, Frokjaer VG, Sundström-Poromaa I. Functional and molecular neuroimaging of menopause and hormone replacement therapy. Front Neurosci. 2014;8: 388

38. Shumaker SA, Legault C, Rapp SR, et al. Estrogen plus progestin and the incidence of dementia and mild cognitive impairment in postmenopausal women: the Women's Health Initiative Memory Study: a randomized controlled trial. JAMA. 2003;289(20): 2651-2662.

39. Espeland MA, Rapp SR, Shumaker SA, et al. Conjugated equine estrogens and global cognitive function in postmenopausal women: Women's Health Initiative Memory Study. JAMA. 2004;291(24):2959-2968.

40. Miller VM, Naftolin F, Asthana S, et al. The Kronos Early Estrogen Prevention Study (KEEPS): what have we learned? Menopause. 2019;26(9):1071-1084.

41. Henderson VW, St John JA, Hodis HN, et al. Cognitive effects of estradiol after menopause: a randomized trial of the timing hypothesis. Neurology. 2016;87(7):699-708.

42. De Bondt T, Jacquemyn Y, Van Hecke W, Sijbers J, Sunaert S, Parizel PM. Regional gray matter volume differences and sex-hormone correlations as a function of menstrual cycle phase and hormonal contraceptives use. Brain Res. 2013;1530:22-31.

43. Pletzer B, Kronbichler M, Aichhorn M, Bergmann J, Ladurner G, Kerschbaum HH. Menstrual cycle and hormonal contraceptive use modulate human brain structure. Brain Res. 2010;1348:55-62.

44. Pletzer BA, Kerschbaum HH. 50 Years of hormonal contraception: time to find out, what it does to our brain. Front Neurosci. 2014;8:256.

45. Monteleone P, Mascagni G, Giannini A, Genazzani AR, Simoncini T. Symptoms of menopause: global prevalence, physiology and implications. Nat Rev Endocrinol. 2018; 14(4):199-215.

46. Lord C, Duchesne A, Pruessner JC, Lupien SJ. Measuring indices of lifelong estrogen exposure: self-report reliability. Climacteric. 2009;12(5):387-394.

47. Rocca WA, Grossardt BR, Shuster LT. Oophorectomy, estrogen, and dementia: a 2014 update. Mol Cell Endocrinol. 2014;389(1-2):7-12.

48. Zeydan B, Tosakulwong N, Schwarz CG, et al. Association of bilateral salpingooophorectomy before menopause onset with medial temporal lobe neurodegeneration. JAMA Neurol. 2019;76(1):95-100.

49. Isaacson RS, Hristov $\mathrm{H}$, Saif $\mathrm{N}$, et al. Individualized clinical management of patients at risk for Alzheimer's dementia. Alzheimers Dement. 2019;15(12):1588-1602.

50. Obermeyer CM. Menopause across cultures: a review of the evidence. Menopause. 2000; 7(3):184-192. 


\section{Neurology}

\section{Association of Reproductive History With Brain MRI Biomarkers of Dementia Risk in Midlife \\ Eva Schelbaum, Lacey Loughlin, Steven Jett, et al.}

Neurology 2021;97;e2328-e2339 Published Online before print November 3, 2021

DOI 10.1212/WNL.0000000000012941

This information is current as of November 3, 2021

Updated Information \& Services

References

Citations

Subspecialty Collections

Permissions \& Licensing

Reprints including high resolution figures, can be found at: http://n.neurology.org/content/97/23/e2328.full

This article cites 50 articles, 8 of which you can access for free at: http://n.neurology.org/content/97/23/e2328.full\#ref-list-1

This article has been cited by 1 HighWire-hosted articles: http://n.neurology.org/content/97/23/e2328.full\#\#otherarticles

This article, along with others on similar topics, appears in the following collection(s):

Cognitive aging

http://n.neurology.org/cgi/collection/cognitive_aging

Inclusion, Diversity, Equity, Anti-racism, and Social Justice (IDEAS)

http://n.neurology.org/cgi/collection/all_equity_diversity_and_inclusio n

MRI

http://n.neurology.org/cgi/collection/mri

Information about reproducing this article in parts (figures,tables) or in its entirety can be found online at:

http://www.neurology.org/about/about_the_journal\#permissions

Information about ordering reprints can be found online:

http://n.neurology.org/subscribers/advertise

Neurology $®$ is the official journal of the American Academy of Neurology. Published continuously since 1951, it is now a weekly with 48 issues per year. Copyright Copyright @ 2021 The Author(s). Published by Wolters Kluwer Health, Inc. on behalf of the American Academy of Neurology.. All rights reserved. Print ISSN: 0028-3878. Online ISSN: 1526-632X.

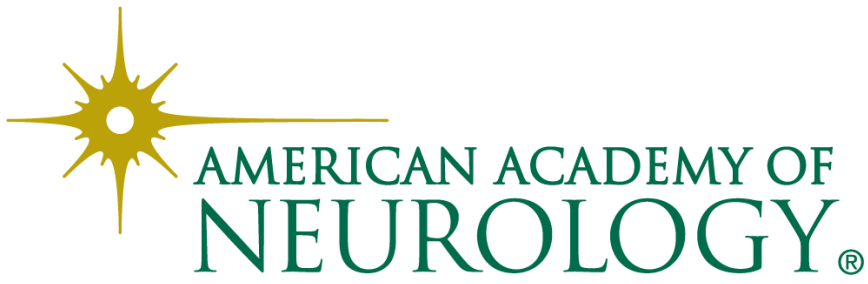

